\title{
Not so soft? Delayed release reduces long-term survival in a passerine reintroduction
}

\author{
Kate Richardson, Isabel C. Castro, Dianne H. Brunton and Doug P. Armstrong
}

\begin{abstract}
Reintroduction success depends in part on the release strategy used. Benefits are attributed to particular release strategies but few studies have tested these assumptions. We examined the effect of delayed release (a form of so-called soft release) on the survival of a threatened passerine, the New Zealand hihi Notiomystis cincta, for up to 7 months after translocation. Birds were captured at the source site and then held in captivity for disease screening. They were then taken to the release site, where 30 were released immediately and 28 were held for a further $2-4$ days in an on-site aviary. Twenty-four birds were fitted with radio-transmitters. A 1,300 ha area around the release site was searched fortnightly, and survival was analysed using a multi-state model that accounted for the effect of transmitters on detection probability. Our results indicated that delayed release had a negative effect on long-term survival, but no effect was apparent in the first 6 weeks. Survival probability from 6 weeks to 7 months postrelease was $0.77 \pm$ SE 0.20 for immediate-release birds and $0.04 \pm$ SE 0.06 for delayed-release birds. Our results suggest that there is a misconception about the benefits of delayedrelease strategies during translocation of wild animals. Studies that have demonstrated a benefit of delayed release in other bird species used captive-bred individuals, and we suggest that wild individuals perceive captivity differently. We recommend that biological context is considered before delayed release is used in translocations.
\end{abstract}

Keywords Hihi, multi-state model, Notiomystis cincta, passerine, reintroduction, release strategy, translocation

\section{Introduction}

$\mathrm{R}$ eintroduction, or returning a species to a part of its Rhistorical range from which it has been extirpated, is increasingly used in the conservation of threatened species (Armstrong \& Seddon, 2008). Reintroductions are often

Kate Richardson* (Corresponding author), Isabel C. Castro and Doug P. Armstrong Wildlife Ecology Group, Te Kura Mātauranga o ngā Taonga ā Papatuanuku, Massey University, Private Bag 11222, Palmerston North 4442, New Zealand. E-mail k.richardson@massey.ac.nz

Dianne H. BRunton Ecology and Conservation Group, Institute of Natural and Mathematical Sciences, Massey University, Albany, New Zealand

${ }^{*}$ Also at: Institute of Zoology, Zoological Society of London, Regent's Park, London, UK

Received 11 January 2013. Revision requested 25 February 2013.

Accepted 25 June 2013. First published online 19 November 2013 unsuccessful and a more experimental or adaptive approach has been advocated to identify the factors that determine the success or failure of such projects (Armstrong et al., 1994; Sarrazin \& Barbault, 1996; Seddon et al., 2007).

The success of a reintroduction is partly dependent on the translocation procedure and whether a 'hard' or 'soft' release strategy is employed (Scott \& Carpenter, 1987). Hard release involves releasing individuals into the new environment immediately, without any assistance such as provision of supplementary food or shelter. Soft release involves a delayed release, with animals held on-site prior to release, and can also include the provision of supplementary food or other resources after release.

The release strategy used in translocations must be considered carefully but there are few data available on the relationship between release strategies and post-release survival probabilities (Armstrong \& Seddon, 2008). Both hard and soft release strategies have potential costs and benefits. Some authors recommend delayed release as a precaution (Wanless et al., 2002; Teixeira et al., 2007; Mitchell et al., 2011), suggesting that holding individuals in captivity on-site can provide an opportunity for them to recover from the capture and handling process and possibly enhance the potential for individuals to become siteattached. However, studies of wild-to-wild bird translocations have shown that delayed release has a negative effect (Komdeur, 1994; Castro et al., 1995; Becker et al., 2010) or in some cases no effect (Lovegrove, 1996). In contrast, studies of wild-to-wild mammalian translocations have demonstrated a benefit of delayed release (Bright \& Morris, 1994; Hamilton et al., 2010), as have studies of captive-towild translocations of birds (Mitchell et al., 2011). Jones \& Merton (2012) advocated delayed release for captive-bred birds but immediate release for wild birds. Experimental data suggest that the procedures associated with translocation (including a captive period) have a cumulative effect that can contribute to long-term changes in the stress physiology of wild birds (Dickens et al., 2009, 2010). Although the specific stressors vary between species and translocations, three unifying themes that define a stressor have emerged: lack of control, unpredictability and novelty (Parker et al., 2012). A captive period prior to release can include all of these.

The hihi is a forest passerine endemic to New Zealand. It was once widespread throughout the North Island but by the 1880 s was reduced to a single population on a 3,083 ha offshore island (Little Barrier Island/Hauturu, Fig. 1). This decline is attributed to a combination of predation by 


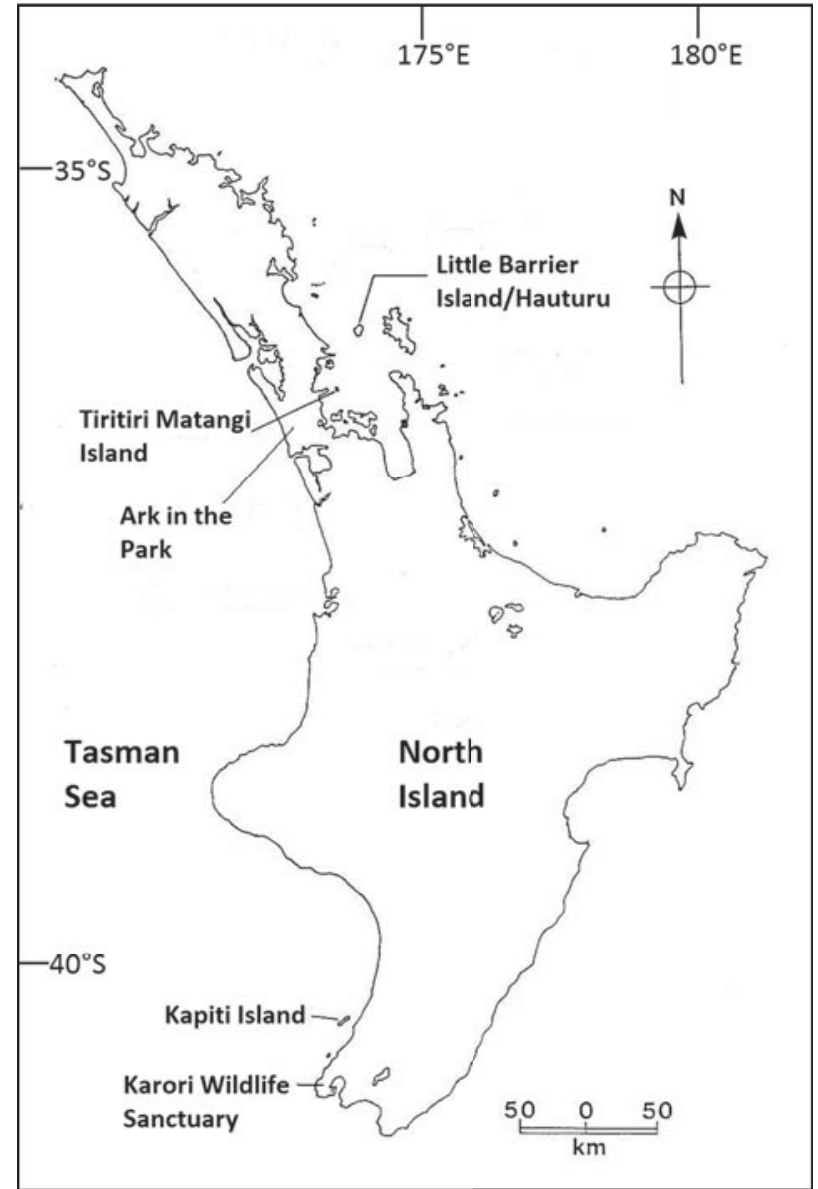

FIG. 1 North Island, New Zealand, showing the location of the remnant population of hihi Notiomystis cincta (Little Barrier Island) and reintroduction sites to 2008 (Tiritiri Matangi and Kapiti Islands, Karori Wildlife Sanctuary, and Ark in the Park).

introduced mammals, habitat clearance and perhaps disease (Taylor et al., 2005). The species is categorized as Vulnerable on the IUCN Red List of Threatened Species (IUCN, 2012). It has been reintroduced to five islands and four mainland sites, with varying levels of success.

Here we examine the effect of delayed release on the survival of wild hihi Notiomystis cincta following translocation, over two time scales: immediate post-release survival (first 6 weeks) and longer-term survival to first breeding season (up to c. 7 months post-release).

\section{Study area}

Our source site was Tiritiri Matangi Island, a 220 ha Scientific Reserve in the Hauraki Gulf, north east of Auckland, New Zealand (Fig. 1). Hihi were reintroduced to Tiritiri Matangi in 1995 and by 2005 the population was sufficiently large for use as a source population for subsequent reintroductions. The population is managed through supplementary feeding and provision of nest boxes
(Taylor et al., 2005) and all hihi are colour banded in the nest at 21 days of age.

Our release site was a mainland restoration area known as Ark in the Park, in the Waitakere Ranges, west of Auckland (Fig. 1). The area has mature native forest considered suitable for hihi, and the restoration involves control of predatory exotic mammals (Bellingham et al., 2008). In 2007 this predator control covered an area of 1,300 ha, located within a contiguous 13,000 ha forest.

\section{Methods}

Pre-release management

We carried out two translocations of 59 hihi in total in February and June 2007 (Table 1). For each translocation we used mist nets and feeder traps to catch birds on Tiritiri Matangi over 4 days. The birds were placed in cloth bags and taken immediately to a processing room, where blood, faecal and cloacal swab samples were taken, in compliance with disease-screening requirements (Ewen et al., 2012). The birds were then kept in an $8 \times 6 \times 2.5 \mathrm{~m}$ aviary on Tiritiri Matangi while the samples were processed (12-14 days in February and 9-12 days in June), which was standard practice in previous successful translocations. The aviary contained fresh vegetation and the birds were fed twice daily. More detailed information on the catching and release protocol used in the translocation is available in Richardson \& Jack (2008).

\section{Release protocol}

On the day of translocation we began catching the birds in the aviary 1 hour after dawn, to ensure that they had an opportunity to feed. All vegetation was carefully removed from the aviary and handnets were used to catch the birds. All birds were re-weighed and 12 had radio-transmitters attached. They were then placed in transfer boxes (2-3 birds per box, separated by sex, age and release strategy), transferred to the mainland by ferry (c. 15 minutes) and then to Ark in the Park by van (c. 1 hour).

In the February translocation c. $50 \%$ of the birds were released immediately and the remaining birds were placed in an on-site aviary $(4 \times 2 \times 2 \mathrm{~m})$ for 4 days (Table 1 ). The same procedure was carried out in June but the birds were released from the aviary after only 2 days because of concerns about aggression between birds. One adult male was found dead in the aviary at the time of release and was excluded from the analysis. Like the Tiritiri Matangi aviary, the Ark in the Park aviary was filled with fresh vegetation and the birds were fed twice daily, with the same diet and by the same personnel as on Tiritiri Matangi. More 
TABLE 1 Numbers of adult male, juvenile male and juvenile female hihi Notiomystis cincta released at Ark in the Park (Fig. 1) in February and June 2007 , with the number carrying transmitters in parentheses.

\begin{tabular}{|c|c|c|c|c|c|c|}
\hline & \multicolumn{3}{|l|}{ February } & \multicolumn{3}{|l|}{ June } \\
\hline & Immediate & Delayed & Total & Immediate & Delayed & Total \\
\hline Adult males & $2(1)$ & $3(1)$ & $5(2)$ & $1(0)$ & $2(1)$ & $3(1)$ \\
\hline Juvenile males & $6(2)$ & $7(4)$ & $13(6)$ & $8(3)$ & $5(3)$ & $13(6)$ \\
\hline Juvenile females & $6(2)$ & $6(2)$ & $12(4)$ & $7(3)$ & $5(2)$ & $12(5)$ \\
\hline Total & $14(5)$ & $16(7)$ & $30(12)$ & $16(6)$ & $12(6)$ & $28(12)$ \\
\hline
\end{tabular}

detailed information is available in Richardson \& Jack (2008).

\section{Post-release management}

Control of introduced mammalian predators is often the most critical aspect of translocations of threatened species to the mainland in New Zealand. It can be in the form of eradication (such as on offshore islands or where predatorproof fences have been constructed) or ongoing control. In 2007 predators (specifically rats, mustelids, cats and possums) were controlled over 1,300 ha at Ark in the Park (Bellingham et al., 2008). Hihi are thought to be vulnerable to such predators, and this was the first reintroduction where predators persisted at low levels.

There were seven supplementary feeder stations within $500 \mathrm{~m}$ of the release site at Ark in the Park. These were of the same design as those used at the source site. Supplementary food (sugar water) is provided at all hihi reintroduction sites, to enhance survival and reproductive success (Chauvenet et al., 2012; Low et al., 2012).

Hihi at the source site primarily breed in artificial nest boxes, as opportunities for natural nest cavities are limited. There were 60 such boxes at the release site but all observed breeding attempts were in natural cavities (Warneford \& Gietl, 2008).

\section{Post-release monitoring}

We walked along set tracks within Ark in the Park at least every second day to detect telemetry signals from the radiotagged birds. The operating life of the transmitters was 1-8 weeks. The tracks were selected to ensure even coverage of the area and to maximize telemetry coverage. Searches were also carried out beyond the Park boundaries, up to $6 \mathrm{~km}$ from the release site, to detect radio-tagged individuals that had left the Park. Further monitoring was carried out by dividing the Park into six areas and searching each once per fortnight until the end of September 2007, listening for hihi and attempting to attract birds using call playback. From September monitoring focused on breeding attempts of known hihi.

We monitored each supplementary feeder station weekly and recorded the band combinations of visiting birds.

\section{Data analysis}

We analysed post-release survival using the multi-state with live recaptures only model in MARK (White \& Burnham, 1999). Using the multi-state model we could account for the effect of transmitters on detection probability by having two states: $\mathrm{T}$, where a bird was carrying a working transmitter, and $\mathrm{N}$, where a bird was not carrying a working transmitter. The encounter histories file recorded $\mathrm{T}, \mathrm{N}$ or o (not detected) for each individual for each fortnightly survey. All models considered estimated separate detection probabilities for birds in states $\mathrm{T}$ and $\mathrm{N}$, and the probability of transition from $\mathrm{T}$ to $\mathrm{N}$ for each of the first 4 fortnights after release. This transition took place either when the transmitter fell off or when the battery failed. The probability of transition from $\mathrm{N}$ to $\mathrm{T}$ was fixed at 0 .

We began with a preliminary analysis to assess potential effects of sex, season of release (seas), and time since release (time) on fortnightly survival probability. Time after release was divided into three periods ( $0-2$ weeks, 2-4 weeks, 4-6 weeks) and one long period (from 6 weeks post-release to the end of September 2007). We found that season of release and time since release were important factors, with birds released in February having higher short-term survival than those released in June, but there was no indication of an effect of sex. Hence only season of release and time since release were included in subsequent candidate models (Table 2).

We compared 25 candidate models to assess the effect of delayed release $(\mathrm{del})$ and carrying a transmitter $(t x)$ on survival. The $t x$ effect was considered to apply to any bird that was fitted with a transmitter, unlike the state variable. Candidate models differed in whether the $d e l$ and/or $t x$ effects were included and whether these applied to shortterm (first 6 weeks) or longer-term survival, or both (Table 2). If applying to both time frames, the effects could be consistent or different for these time frames. The global model was seas + time $+t x^{\star} S L+\operatorname{del}^{*} S L$, where the del and $t x$ effects applied differently to short- and long-term survival. We assessed goodness of fit of this model, using the bootstrap test in MARK, and estimated the overdispersion parameter $(c)$ by dividing the mean deviance from 1,000 bootstrap data sets by the observed deviance. This gave a 
TABLE 2 Comparison of candidate models for post-release survival of hihi translocated to Ark in the Park (Fig. 1), February-September 2007, in terms of quasi-Akaike information criterion adjusted for overdispersion $(\hat{c}=1.25)$ and small sample size bias (QAIC $)$, difference in $\mathrm{QAIC}_{\mathrm{c}}$ relative to the best model $(\triangle \mathrm{QAIC})$, weight of evidence supporting each model $\left(\mathrm{QAIC}_{\mathrm{c}}\right.$ weight), number of parameters $(K)$, and quasi-deviance.

\begin{tabular}{|c|c|c|c|c|c|}
\hline Model $^{*}$ & QAICc & $\triangle \mathrm{QAICc}$ & QAICc weight & K & Quasi-deviance \\
\hline seas + time + tx $($ short $)+\operatorname{del}($ long $)$ & 341.55 & 0.00 & 0.24 & 13 & 243.34 \\
\hline seas + time + tx + del(long $)$ & 341.89 & 0.34 & 0.20 & 13 & 243.68 \\
\hline seas + time + del(long) & 343.29 & 1.74 & 0.10 & 12 & 247.41 \\
\hline seas + time $+t x^{\star} S L+\operatorname{del}($ long $)$ & 343.80 & 2.25 & 0.08 & 14 & 243.23 \\
\hline seas + time $+t x($ short $)+d e l^{\star} S L$ & 343.83 & 2.29 & 0.08 & 14 & 243.27 \\
\hline seas + time $+t x+\operatorname{del}^{*} S L$ & 344.13 & 2.58 & 0.07 & 14 & 243.56 \\
\hline seas + time + tx $($ long $)+\operatorname{del}($ long $)$ & 345.33 & 3.78 & 0.04 & 13 & 247.12 \\
\hline seas + time $+\operatorname{del}^{*} S L$ & 345.59 & 4.04 & 0.03 & 13 & 247.38 \\
\hline seas + time $+t x^{\star} S L+d e l^{\star} S L$ & 346.09 & 4.54 & 0.02 & 15 & 243.14 \\
\hline seas + time $+t x+$ del & 346.26 & 4.71 & 0.02 & 13 & 248.05 \\
\hline seas + time $+t x($ short $)+$ del & 346.26 & 4.71 & 0.02 & 13 & 248.06 \\
\hline seas + time $+t x$ & 346.92 & 5.37 & 0.02 & 12 & 251.05 \\
\hline seas + time + tx(short $)$ & 347.07 & 5.52 & 0.02 & 12 & 251.19 \\
\hline seas + time + tx $($ long $)+$ del $^{*} S L$ & 347.65 & 6.10 & 0.01 & 14 & 247.08 \\
\hline seas + time + del & 348.06 & 6.51 & 0.01 & 12 & 252.18 \\
\hline seas + time & 348.10 & 6.55 & 0.01 & 11 & 254.52 \\
\hline seas + time $+t x^{\star} S L+$ del & 348.35 & 6.80 & 0.01 & 14 & 247.78 \\
\hline seas + time $+t x+$ del(short $)$ & 348.98 & 7.43 & 0.01 & 13 & 250.77 \\
\hline seas + time $+t x^{\star} S L$ & 349.12 & 7.57 & 0.01 & 13 & 250.91 \\
\hline seas + time + tx $($ short $)+$ del $($ short $)$ & 349.15 & 7.60 & 0.01 & 13 & 250.94 \\
\hline seas + time + tx (long) + del & 349.96 & 8.41 & 0.00 & 13 & 251.75 \\
\hline seas + time $+t x($ long $)$ & 349.98 & 8.44 & 0.00 & 12 & 254.11 \\
\hline seas + time + del (short) & 250.29 & 8.74 & 0.00 & 12 & 254.42 \\
\hline seas + time $+t x^{\star} S L+\operatorname{del}($ short $)$ & 351.20 & 9.66 & 0.00 & 14 & 250.64 \\
\hline
\end{tabular}

${ }^{*}$ The models consider the effects of release date (seas), time after release (time), whether or not a bird had a transmitter $(t x)$, and if the release was immediate or delayed (del). The $t x$ and del effects may apply only to the first 6 weeks after release (short) or between 6 weeks and up to 7 months (long), or there may be different effects for these different time periods $\left({ }^{*} S L\right)$.

value of $\hat{\mathrm{c}}=1.25$, indicating some overdispersion, but correcting for this did not alter the ranking of the models.

\section{Results}

Comparing models showed that delayed release reduced survival over the longer time frame (between 6 weeks and 7 months). The top four models, which account for $62 \%$ of the corrected quasi Akaike information criterion weight (Table 2), all include a long-term effect but no short-term effect of delayed release. The only other models with reasonable support included separate effects of delayed release in both long and short periods but the effect over the short term was estimated to be negligible. Based on the fortnightly survival probabilities estimated using the best model ( 0.98 for immediate release and 0.8 for delayed release; Fig. 2), the overall probability of surviving the 6 months after the initial 6 weeks was estimated to be $0.77 \pm$ SE 0.20 for immediate-release birds and $0.04 \pm$ SE 0.06 for delayed-release birds.

The results for effect of carrying a transmitter are more ambiguous than those for release strategy. The best model

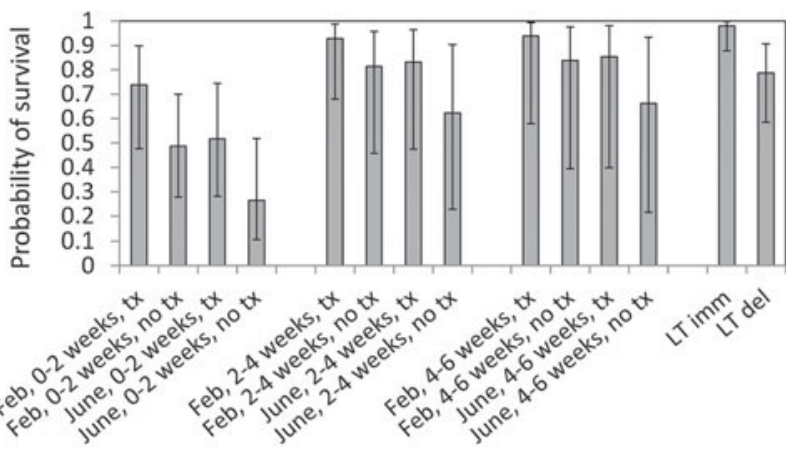

FIG. 2 Fortnightly survival probabilities (from best model,

$\{S($ seas + time $+t x($ short $)+\operatorname{del}($ long $))\}$; Table 2) for hihi at Ark in the Park (Fig. 1), with 95\% confidence intervals. LT (long term) $\geqslant 6$ weeks post-release, $\mathrm{tx}=$ transmitter, $\mathrm{imm}=$ immediate release, del $=$ delayed release. The multi-state model estimates separate detection probabilities for birds with and without transmitters ( $\mathrm{T}$ and $\mathrm{N}$, respectively) thus accounting for the differential capacity to detect each group.

suggests a short-term effect of carrying a transmitter (apparently increasing survival; Fig. 2). However, the next three models indicate an effect of transmitters over the 
whole period, no effect of transmitters or a differential effect over both time periods (Table 2).

\section{Discussion}

Our study showed that a delayed-release strategy can have a negative effect on survival well beyond the first weeks of release. The results suggest that the costs of delayed release outweigh the benefits. However, delayed-release strategies are commonly recommended for translocations (Wanless et al., 2002; Teixeira et al., 2007; Mitchell et al., 2011) despite the lack of information about the positive or negative effects on post-release survival and behaviour of wild animals. Our results corroborate and expand the findings of others (Castro et al., 1995; Dickens et al., 2009, 2010) to suggest that delayed release for wild-caught bird species may compromise the success of a translocation rather than improve the outcome.

We found that survival probabilities were decreased for delayed-release birds between 6 weeks and 7 months postrelease. Immediate-release birds had a $77 \%$ chance of surviving this period, compared with $4 \%$ for delayed-release birds. Although we were not able to measure long-term physiological changes, the decreased survival probability in the delayed-release group suggests that these individuals were less able to adapt to their new environment than the immediate-release group. Although all birds were held in captivity prior to release at the source site, for disease screening and to allow time to capture a sufficient number of birds, the delayed-release birds endured a longer total captivity time and an additional transfer to a novel environment (the on-site aviary), with a different group of birds and a change in personnel and feeding routines. This meets all three scenarios that can constitute a stressor as outlined by Parker et al. (2012): lack of control, unpredictability and novelty.

In an experiment using chukar partridges Alectoris chukar Dickens et al. (2009) found there was an additive effect of the stressors involved in translocation (handling, captivity, and introduction to a novel environment). Similarly Waas et al. (1999) demonstrated a cumulative physiological response that peaked during the transitional stages of translocation of red deer Cervus elaphus (i.e. during movement between captivity and modes of transport) and recommended that the number of transitional events be reduced. Aggression between birds was observed in June (and was associated with the mortality of the adult male in the on-site aviary) but not in February and may have been an additional contributing factor, with social stress known to cause changes in hormonal stress response in other species (Bhatnagar et al., 2006). Adult hihi are territorial, and in June juveniles are beginning to establish territories for their first breeding season. In contrast, in February juvenile hihi tend to be more social and forage together in crèches; hence they may be better able to adjust to captivity than juveniles in June. We suggest that the combination of these factors increased the probability of some individuals becoming chronically stressed and that this resulted in differential survival probabilities between the two groups between 6 weeks and 7 months post-release.

Two previous studies examined the effect of release strategy on hihi survival in the short term (up to 6 weeks post-release). The translocation of hihi to Karori Wildlife Sanctuary in 2005 followed a similar protocol to this study and found no effect of delayed release in the first 6 weeks (Empson \& Booth, 2007). In contrast, Castro et al. (1995) found that delayed-release hihi had lower survival in the first 4 weeks (46\%) compared to hihi that were released immediately $(75 \%)$ on Kapiti Island. It is difficult to compare these studies and our study because of differences in the translocation protocols. The Kapiti translocation took place later in the year, used adult birds rather than juveniles and involved a greater total captivity time. Potentially these factors may have combined to produce a greater effect on the survival of delayed-release birds in the first 4 weeks than was the case in our study. An effect was not looked for beyond this period. In our study it may be that, with both groups subject to a captive period at the source site, all birds suffered the effects of translocation stress to some degree but that these effects persisted longer in the delayed-release birds; hence the difference was only apparent over the longer time frame. In February the immediate-release birds were released into an environment that did not contain existing hihi, presenting a possible confounding factor, although the size of the area makes it unlikely that the first birds to be released had any major competitive advantage.

The significance of the long-term effects of stress associated with translocations is becoming increasingly recognized. Dickens et al. (2009) demonstrated that physiological changes persisted beyond exposure to these stressors, with a single capture event being sufficient to cause a long-term decrease in endocrine responsiveness. Chronic stress can result in immune and reproductive suppression, altered metabolism and a decrease in fight-orflight responsiveness (Dickens et al., 2010; Parker et al., 2012) that may make translocated individuals more vulnerable to pathogens and predators long after release, thus increasing the likelihood of translocation failure (Dickens et al., 2010). Different aspects of the translocation process cause stress to different species and perhaps even individuals. We therefore encourage replication of this study in other species and situations. We note that studies that have demonstrated or suggested a benefit of delayed release in birds have referred to captive-bred individuals (Wanless et al., 2002; Mitchell et al., 2011) and we believe that the perception of a stressor differs significantly between wild and captive-bred individuals (Jones \& Merton, 2012; Parker et al., 2012). It should 
not be assumed that results from such studies will also apply to translocations of wild animals. With wild-to-wild translocations the priority must be to minimize stress and transfer individuals from the source to the release site as quickly as can be appropriately managed. Captive-to-wild translocations are different and the focus must be on ensuring that the animals have the necessary skills and behaviour to survive the transition from captivity to a wild environment.

A third translocation of hihi to Ark in the Park occurred in 2008, using immediate-release methods only. Post-release monitoring was limited in comparison to 2007 but a higher percentage of hihi from this translocation apparently survived to the first breeding season than in 2007 (Warneford \& Gietl, 2008). Beyond this period birds from both translocations declined and had disappeared from the site by 2011. We attribute the failure of this population to persist in the long term to predation by a small number of mammalian predators, although this has not been demonstrated conclusively. Increased susceptibility to predation is one effect of chronic stress and is a potential explanation for the lower survival probabilities of the delayed-release birds in 2007. Hihi both nest and roost in tree cavities, leaving them extremely vulnerable to predation by introduced mammals year-round, and this is thought to be the primary reason for their original extirpation from mainland New Zealand.

Our results emphasize the need to monitor reintroductions beyond the initial post-release period (i.e. the first few weeks), and to investigate the effects of translocation strategies over longer time periods. The cumulative effects of stress have the potential to undermine translocation success and we suggest that captive periods for wild animals and the number of transition events be minimized unless there is a good reason not to do so. Captivity should never be assumed to be beneficial or benign for wild animals and we advocate careful consideration of the effects of delayed release before this is considered as a release strategy.

\section{Acknowledgements}

Thanks to Ark in the Park for providing funding and support to Kate Richardson. Thanks also to Ark volunteers and contractors for assisting with monitoring, to the translocation team on Tiritiri Matangi Island for the transfer of birds to Ark in 2007, to the Hihi Recovery Group and Department of Conservation for ongoing support, and to Kevin Parker, Molly Dickens and two anonymous reviewers for their helpful comments on this manuscript. All work was undertaken with a Department of Conservation High Impact Research Permit AK-20621-FAU and with approval from the Massey University Animal Ethics Committee.

\section{References}

Armstrong, D.P. \& Seddon, P.J. (2008) Directions in reintroduction biology. Trends in Ecology and Evolution, 23, 20-25.

Armstrong, D.P., Soderquist, T. \& Southgate, R. (1994) Designing experimental reintroductions as experiments. In Reintroduction Biology of Australian and New Zealand Fauna (ed. M. Serena), pp. 27-29. Surrey Beatty and Sons, Chipping Norton, Australia.

Becker, D., Massey, G., Groombridge, J. \& Hammond, R. (2010) Moving i'iwi (Vestiaria coccinea) as a surrogate for future translocations of endangered 'akohekohe (Palmeria dolei). Pacific Cooperative Studies Unit Technical Report 172. University of Hawai'i at Manoa, Honolulu, Hawai'i.

Bellingham, M., Jack, S., MaKan, T. \& Sumich, J. (2008) Ark in the Park draft restoration plan. Royal Forest and Bird Protection Society, Auckland, New Zealand.

Bhatnagar, S., Vining, C., Iyer, V. \& Kinni, V. (2006) Changes in hypothalamic-pituitary-adrenal function, body temperature, body weight and food intake with repeated social stress exposure in rats. Journal of Neuroendocrinology, 18, 13-24.

Bright, P.W. \& Morris, P.A. (1994) Animal translocation for conservation-performance of dormice in relation to release methods, origin and season. Journal of Applied Ecology, 31, 699-708.

Castro, I., Alley, J.C., Empson, R.A. \& Minot, E.O. (1995) Translocation of hihi or stitchbird Notiomystis cincta to Kapiti Island, New Zealand: transfer techniques and comparison of release strategies. In Reintroduction Biology of Australian and New Zealand Fauna (ed. M. Serena), pp. 113-120. Surrey Beatty and Sons, Chipping Norton, Australia.

Chauvenet, A.L.M., Ewen, J.G., Armstrong, D.P., Coulson, T., Blackburn, T.M., Adams, L. et al. (2012) Does supplemental feeding affect the viability of translocated populations? The example of the hihi. Animal Conservation, 15, 337-350.

Dickens, M.J., Delehanty, D.J. \& Romero, L.M. (2009) Stress and translocation: alterations in the stress physiology of translocated birds. Proceedings of the Royal Society of London B: Biological Sciences, 276, 2051-2056.

Dickens, M.J., Delehanty, D.J. \& Romero, L.M. (2010) Stress: an inevitable component of animal translocation. Biological Conservation, 143, 1329-1341.

Empson, R. \& Воотн, M. (2007) Transfer of hihi (stitchbirds) from Tiritiri Matangi Island and NWC (Mt Bruce) to Karori Wildlife Sanctuary 2005. Internal report to Department of Conservation/ Hihi Recovery Group.

Ewen, J.G., Armstrong, D.P., Empson, R., Jack, S., Makan, T., McInnes, K. et al. (2012) Parasite management in translocations: lessons from a threatened New Zealand bird. Oryx, 46, 446-456.

Hamilton, L.P., Kelly, P.A., Williams, D.F., Kelt, D.A. \& Wittmer, H.U. (2010) Factors associated with survival of reintroduced riparian brush rabbits in California. Biological Conservation, 143, 999-1007.

IUCN (2012) IUCN Red List of Threatened Species v. 2012.2. $\mathrm{Http} / /$ www.iucnredlist.org [accessed 29 November 2012].

Jones, C.G. \& Merton, D.V. (2012) A tale of two islands: the rescue and recovery of endemic birds in New Zealand and Mauritius. In Reintroduction Biology: Integrating Science and Management (eds J.G. Ewen, D.P. Armstrong, K.A. Parker \& P.J. Seddon), pp. 33-72. Wiley-Blackwell, Oxford, UK.

Komdeur, J. (1994) Conserving the Seychelles warbler Acrocephalus sechellensis by translocation from Cousin Island to the islands of Aride and Cousine. Biological Conservation, 67, 143-152. 
Lovegrove, T.G. (1996) Island releases of saddlebacks Philesturnus carunculatus in New Zealand. Biological Conservation, 77, 151-157.

Low, M., MAKan, T. \& CAstro, I. (2012) Food availability and offspring demand influence sex-specific patterns and repeatability of parental provisioning. Behavioral Ecology, 23, 25-34.

Mitchell, A.M., Wellicome, T.I., Brodie, D. \& Cheng, K.M. (2011) Captive-reared burrowing owls show higher site-affinity, survival, and reproductive performance when reintroduced using a soft-release. Biological Conservation, 144, 1382-1391.

Parker, K.A., Dickens, M.J., Clarke, R.H., \& Lovegrove, T.G. (2012) The theory and practice of catching, holding, moving and releasing animals. In Reintroduction Biology: Integrating Science and Management (eds J.G. Ewen, D.P. Armstrong, K.A. Parker \& P.J. Seddon), pp. 105-137. Wiley-Blackwell, Oxford, UK.

RiCHARDSON, K. \& JACK, S. (2008) Transfer report on the translocation of hihi/stitchbird (Notiomystis cincta) from Tiritiri Matangi Island to the Ark in the Park site, Waitakere Ranges Regional Park, Auckland on 23 February and 16 June 2007. Internal report to Department of Conservation, New Zealand.

Sarrazin, F. \& Barbault, R. (1996) Reintroduction: challenges and lessons for basic ecology. Trends in Ecology and Evolution, 11, 474-478.

Scott, J.M. \& Carpenter, J.W. (1987) Release of captive-reared or translocated endangered birds: what do we need to know? Auk, 104, 544-545.

Seddon, P.J., Armstrong, D.P. \& Maloney, R.F. (2007) Developing the science of reintroduction biology. Conservation Biology, 21, 303-312.

Taylor, S., Castro, I. \& Griffiths, R. (2005) Hihi/stitchbird (Notiomystis cincta) Recovery Plan 2004-09. Threatened Species Recovery Plan 54. Department of Conservation, Wellington, New Zealand.
Teixeira, C.P., Schetini de Azevedo, C., Mendl, M., Cipreste, C.F. \& Young, R.J. (2007) Revisiting translocation and reintroduction programmes: the importance of considering stress. Animal Behaviour, 73, 1-13.

WaAs, J.R., Ingram, J.R. \& Matthews, L.R. (1999) Real-time physiological responses of red deer to translocations. Journal of Wildlife Management, 63, 1152-1162.

Wanless, R.M., Cunningham, J., Hockey, P.A.R., Wanless, J., White, R.W. \& Wiseman, R. (2002) The success of a soft-release reintroduction of the flightless Aldabra rail (Dryolimnas [cuvieri] aldabranus) on Aldabra Atoll, Seychelles. Biological Conservation, 107, 203-210.

Warneford, A. and Gietl, A. (2008) Ark in the Park Hihi Monitoring Contract Report, 2007/08 Breeding Season. Royal Forest and Bird Protection Society, Auckland, New Zealand.

White, G.C. \& Burnham, K.P. (1999) Program MARK: survival estimation from populations of marked animals. Bird Study, 46 (Supplement), 120-138.

\section{Biographical sketches}

KATE RICHARDSON researches hihi reintroductions to mainland sites in New Zealand, with a focus on dispersal behaviour of hihi at Maungatautari Ecological Island. Is a BEL C. CASTRO's research focuses on behavioural ecology of New Zealand's birds and she has been involved in hihi research since the 1990s. Dianne H. BRUNTON researches social behaviour and the evolution and ecology of animal communication. Doug P. Armstrong's research focuses on the dynamics of small populations. He is chair of the Oceania Section of the IUCN/Species Survival Commission Reintroduction Specialist Group. 